\title{
Preoperative Assessment of the Spinal Cord Vasculature
}

\author{
Alexandre Campos Moraes Amato \\ and Noedir Antonio Groppo Stolf
}

\subsection{Introduction}

Spinal cord ischemia is a rare and devastating complication of aortic aneurysm repair that has a great impact on quality of life and surgical success. Given the difficulty in predicting paraplegia in patients with aortic pathologies, new strategies are being studied to prevent spinal cord injury after aortic surgery.

Surgical repair of thoracoabdominal aneurysms was first described in 1955, and, despite improvements, the risk of spinal cord ischemia remained substantial, between $4 \%$ and $11 \%$, with a mortality risk ranging from $3 \%$ to $17 \%$, even at centers with extensive experience [1-3]. Therefore, the search for a better treatment option is still ongoing. One such improvement was the development of thoracic endovascular aortic repair (TEVAR). Because the technique does not require aortic cross-clamping, has shorter surgery

\footnotetext{
A. C. M. Amato $(\bowtie)$

Vascular Surgery, Santo Amaro University,

São Paulo, SP, Brazil

Amato-Instituto de Medicina Avançada,

São Paulo, SP, Brazil

e-mail: alexandre@ amato.com.br

N. A. G. Stolf

Thoracic and Cardiovascular Surgery, School of

Medicine, University of São Paulo,

São Paulo, SP, Brazil

e-mail: stolf@incor.usp.br
}

times, and involves less invasive procedures, it lowered the incidence of spinal cord ischemia to $1-5 \%$ [4-7], a rate that is nevertheless high.

Understanding the spinal cord (SC) vascular supply is key when treating patients with aortic diseases; however, the SC vasculature is complex and difficult to study because it consists of very small vessels running in intricate, threedimensional planes with highly variable anatomy [8]. Current noninvasive imaging techniques can identify the artery of Adamkiewicz (AKA, also known as arteria radicularis magna) and show spinal cord vasculature; however, their sensitivity and specificity are insufficient, with several factors affecting their detection capability $[9,10]$. Conversely, angiography, formerly considered the gold standard method, is too invasive for current clinical routine use, hence the need for postprocessing of images using three-dimensional multiplanar reconstruction to enhance detection of critical closure sites.

\subsection{Anatomy}

Blood supply to the medulla comes from the intercostal and lumbar arteries, which split three times before reaching the spinal cord, and from the subclavian and hypogastric branches. Except for the hypogastric arteries, which originate from the iliac arteries, the others arise from the aorta. After the first branch, the spinal branch, which 
divides into anterior and posterior radicular arteries, the intercostal artery bifurcates into the dorsal and vertebral branches. Only at some spinal levels do the anterior and posterior radicular arteries penetrate the dura mater, reaching the spinal cord. Only some of the original segmental branches persist into adulthood $(2-14$, mean =6). The anterior spinal artery (ASA), which is a key component of the vascularization of the spinal cord and anterior and lateral funiculi, is basically an anastomotic channel between the ascending and descending branches of neighboring anterior radicular arteries (Fig. 25.1) [11]. The last bifurcation of the spinal branch provides a constant supply of oxygenated blood to the anterior and posterior spinal cord, nerve roots, and dura mater.

Generally, the largest of the anterior radicular arteries, with its characteristic "hairpin" shape, is referred to as the great anterior radicular artery or artery of Adamkiewicz (AKA) (Fig. 25.2) [11].

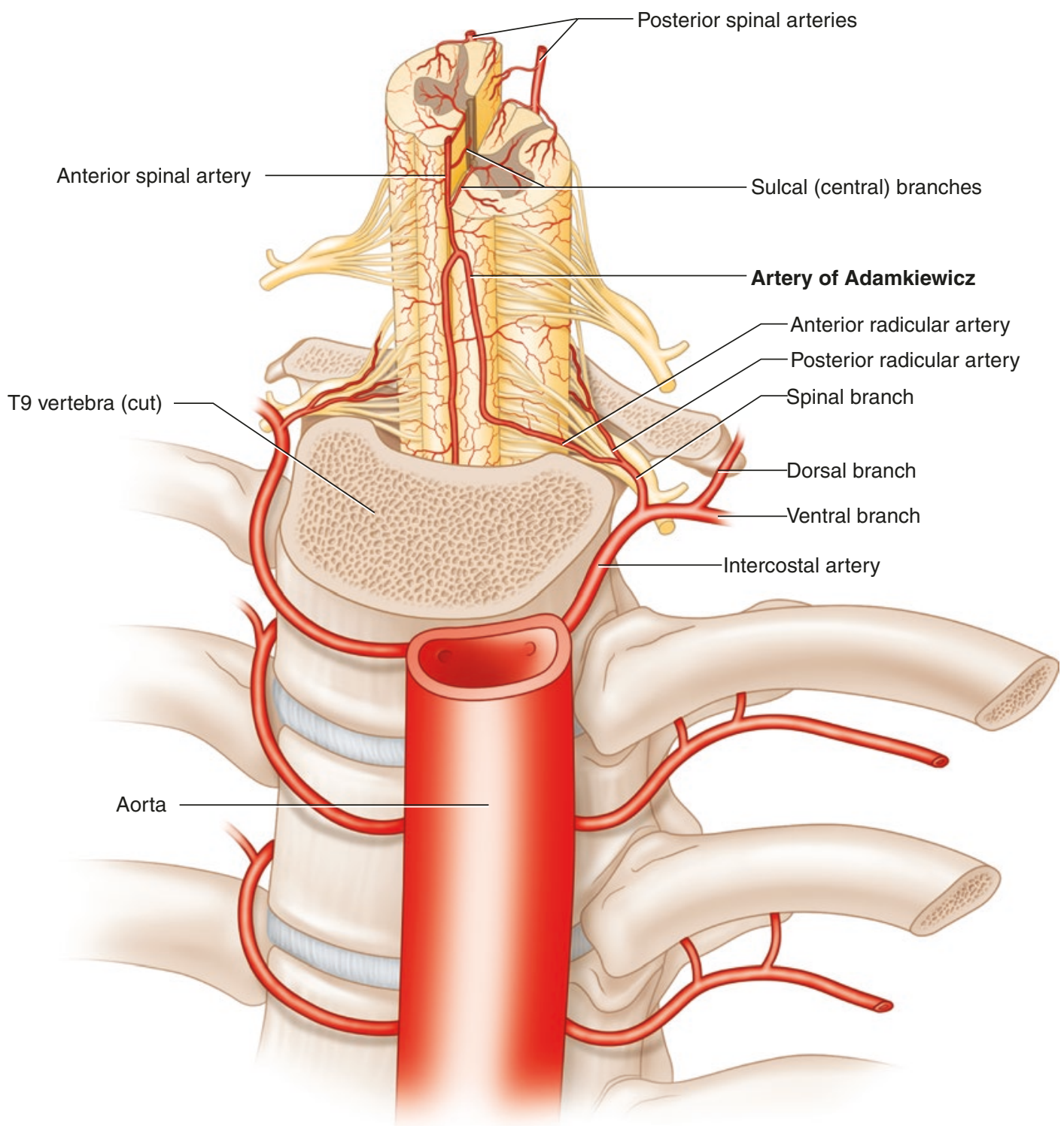

Fig. 25.1 Schematic drawing of the blood supply to the spinal cord [11] 
The posterior radicular artery follows a pattern similar to the anterior radicular artery but gives rise to two longitudinal anastomotic channels, the posterolateral spinal arteries. Arteries that supply the spinal cord are divided into a central system supplied by the sulcal arteries and a peripheral system, the pial plexus, from which the perforating branches originate (Fig. 25.2) [8, 12-14]. The AKA usually originates from a left posterior intercostal artery at the levels of T9-T12 (Fig. 25.6) [9].

The venous drainage of the spinal cord is no less controversial and characterized mainly by the great posterior radicular vein, identified by its "coat hook" appearance, the posterior spinal vein, and the anterior spinal vein [27]. The anatomic significance of venous drainage preoperative planning of aortic surgery lies in its differentiation, in the image exams, from the arterial system (Fig. 25.3). Posteriorly, there is just one posterior spinal vein, as opposed to two posterolateral arteries, which is often larger than the anterior median vein [28].

Even though there is a single identifiable artery supplying the spinal cord at the thoracic level, it is not the only source of medullary blood supply. Griepp et al. refined the anatomic conceptualization of the collateral circulation network for spinal cord blood supply [29] (Fig. 25.4), providing details of its vascular redundancy. There is an axial network of small arteries in the spinal canal, paravertebral tissues, and paraspinal muscles that anastomose with each other and with the nutrient arteries of the spinal cord. Inputs

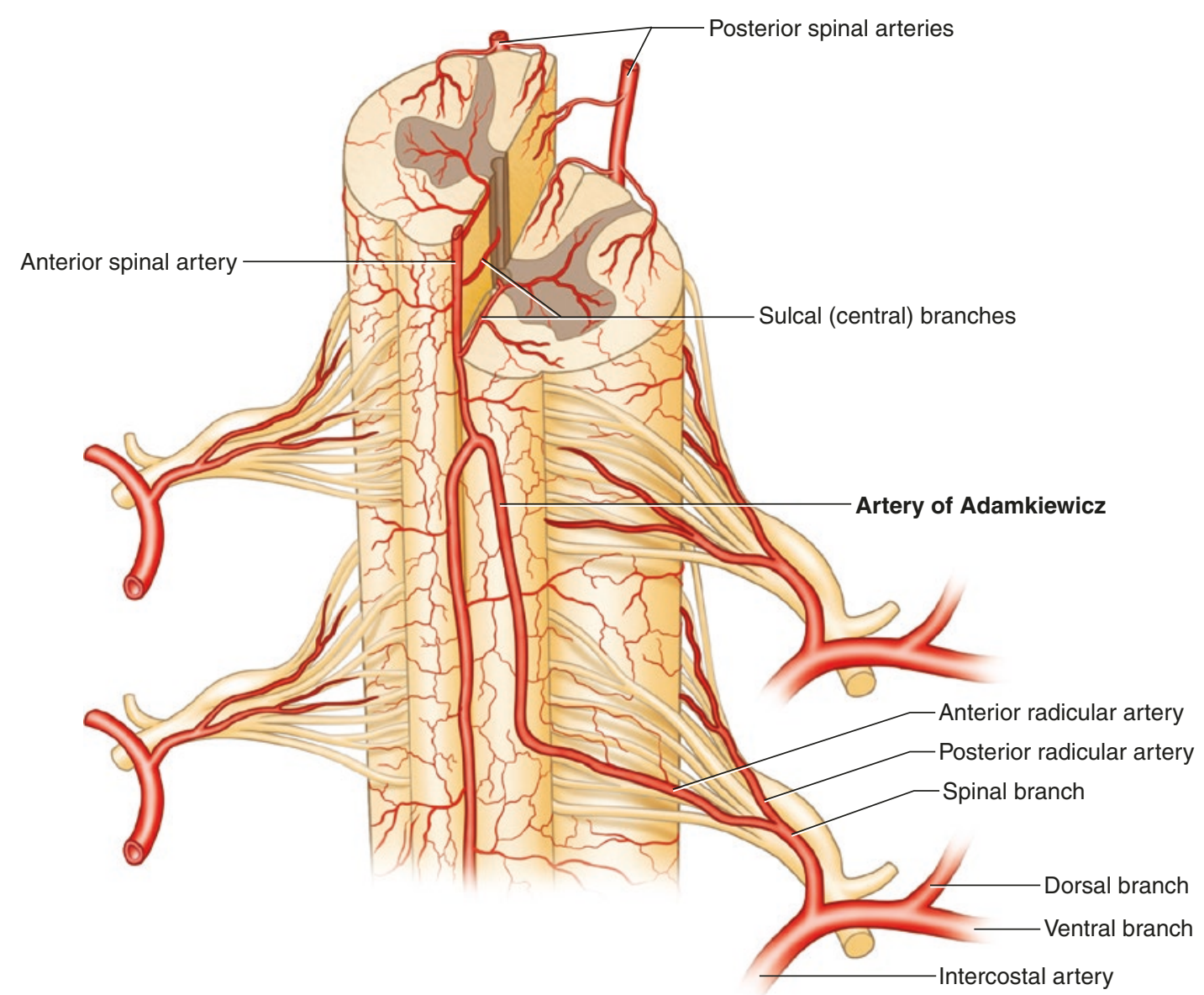

Fig. 25.2 Spinal arterial anatomy showing the artery of Adamkiewicz [11] 


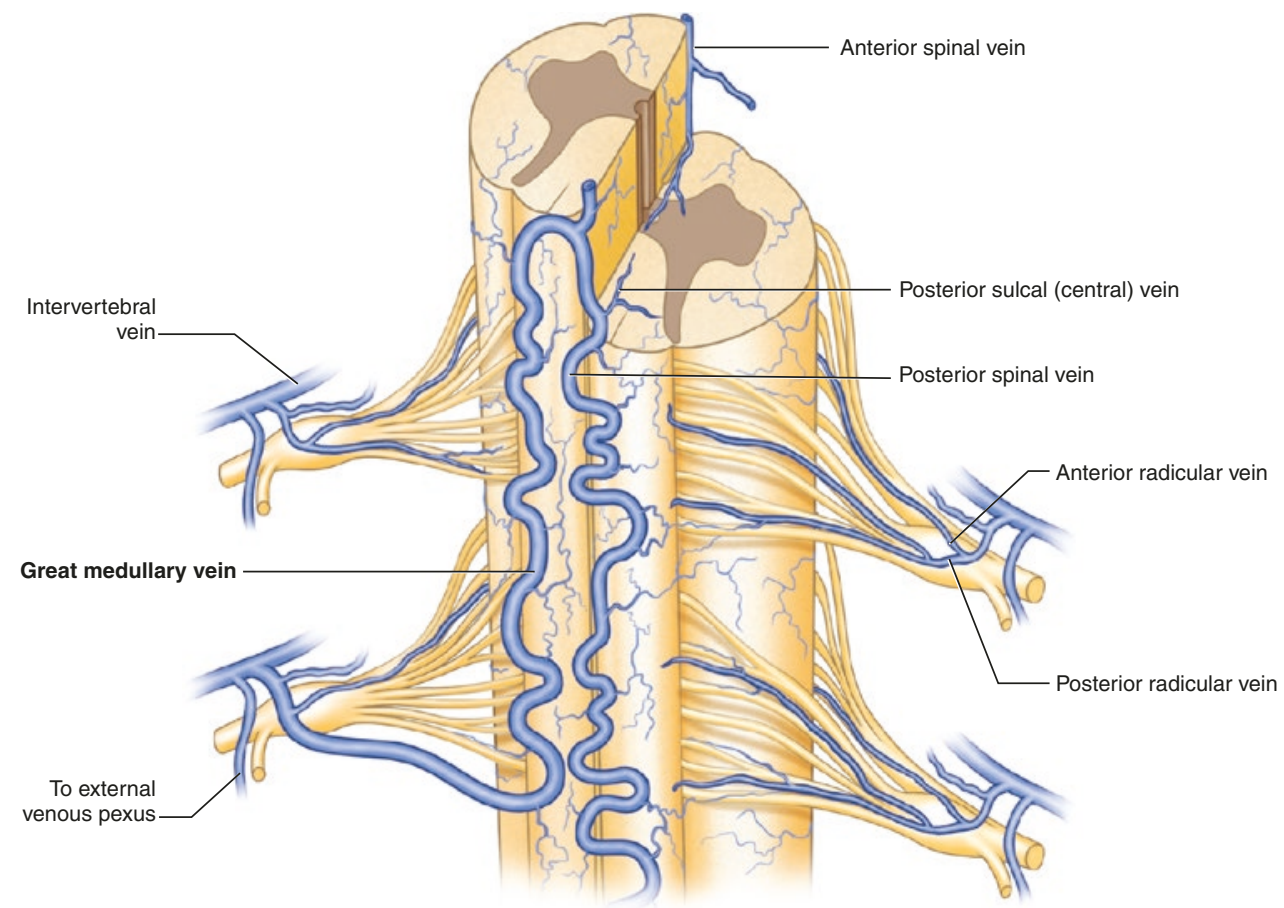

Fig. 25.3 Spinal venous anatomy [11]

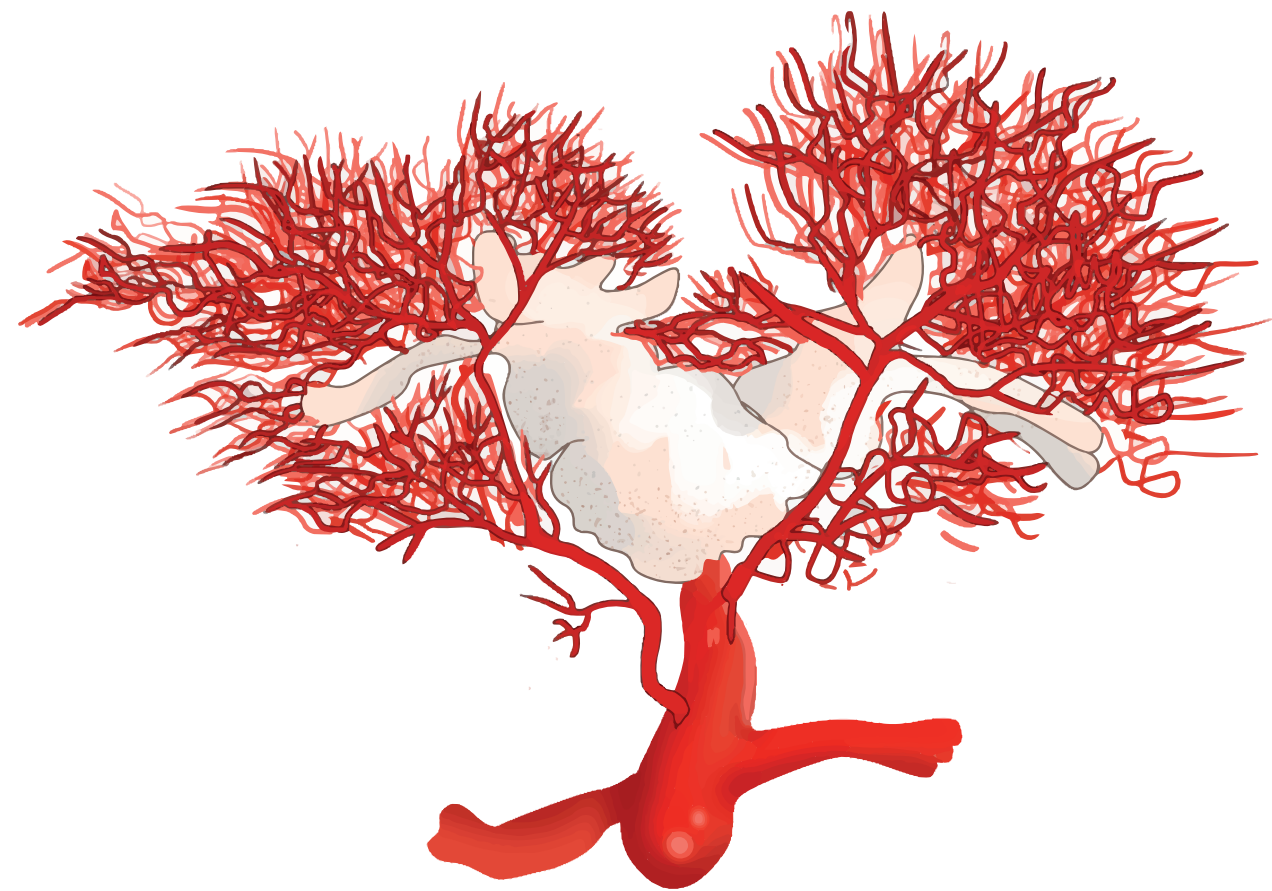

Fig. 25.4 The aorta is seen giving off segmental arteries which course around the vertebral body to supply the paraspinal muscles and, in the midline, the anterior spinal artery. The image shows the extensive anastomotic network for spinal cord blood supply 


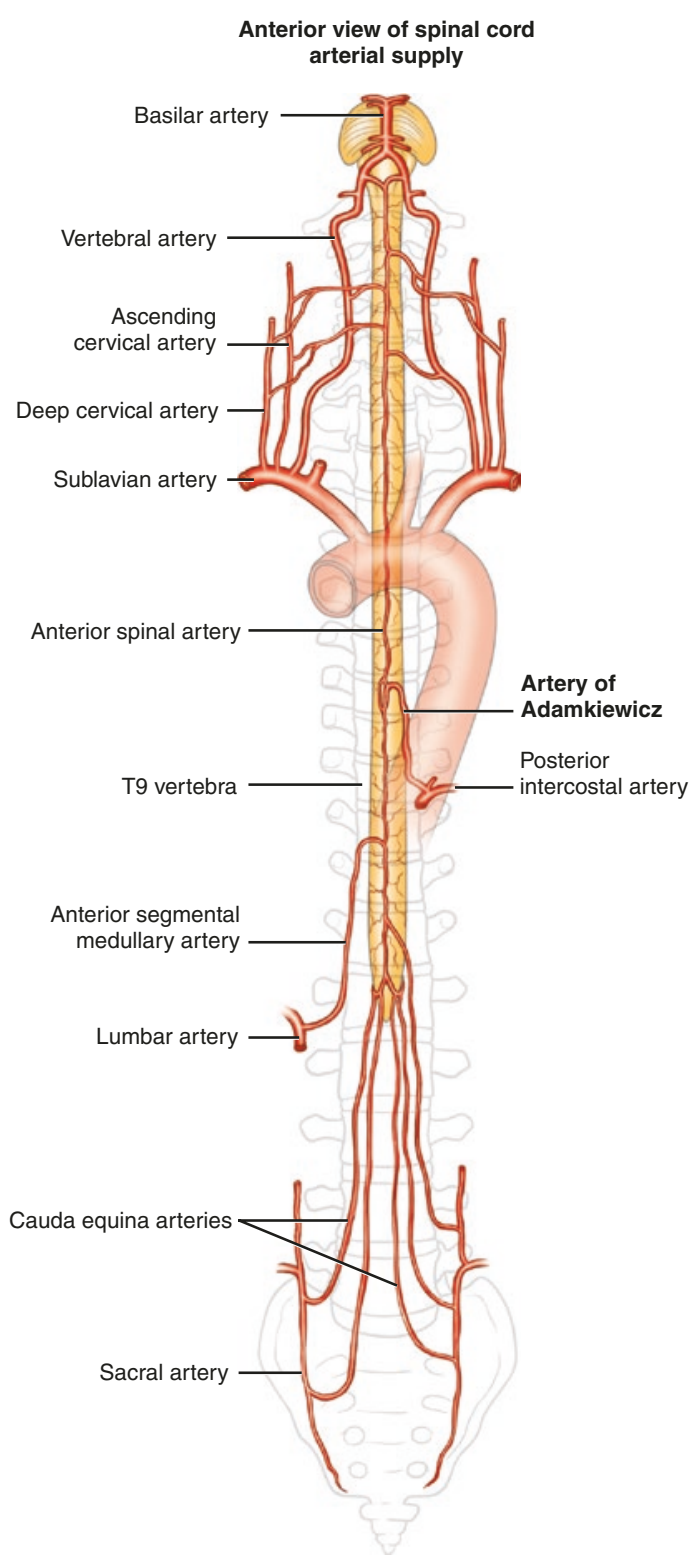

Fig. 25.5 Network of collateral vessels: subclavian, hypogastric, intercostal, and lumbar arteries

into this network include the segmental vessels (intercostal and lumbar arteries), subclavian arteries, hypogastric arteries, and their branches (Fig. 25.5) [30, 31]. In addition to these multiple inputs, there is also an extensive network of epidural arterial and small vessels that supply the paraspinal musculature (Fig. 25.4). All these vessels are interconnected and have anastomoses with the subclavian arteries, cranially, and the hypogastric arteries, caudally [31].

This network of collateral vessels can provide compensatory flow to the spinal cord in the event of occlusion of large caliber vessels [31] and increase cord nutrient flow from one source when another is reduced. Conversely, flow can be decreased if an alternate low resistance pathway is opened, such as when arterial steal occurs [29]. According to Adamkiewicz's partial flow theory, the bloodstreams of the radicular arteries reach the medullary surface in two streams, one running cranially and one caudally [13].

\subsection{Imaging Acquisition Techniques}

The importance of identifying and localizing the artery of Adamkiewicz prior to thoracic and thoracoabdominal surgery to prevent spinal cord injury was demonstrated by Kieffer et al. in the 1980s [32] using angiography. Arterial and posterior radicular arteries and spinal artery branches with calibers greater than 200-400 $\mu \mathrm{m}$ have been demonstrated angiographically [13]; however, this procedure is invasive, and its risks, including the risk of embolization [33], are currently considered unacceptable [34].

Computed tomography angiography (CTA) and magnetic resonance angiography (MRA) are minimally invasive imaging techniques currently used to assess spinal cord blood supply [28]. There is growing evidence that the artery of Adamkiewicz can be identified by these noninvasive techniques [15-21, 33, 35-40]. AKA detection rates range from $67 \%$ to $100 \%$ with MRA [28]; however, this imaging technique is not routinely used for the preoperative assessment of patients with aortic diseases. Conversely, CTA is performed routinely, but AKA detection rates vary widely from $18 \%$ to $100 \%$ [28] depending on post-processing technique, type of scanner, and operator experience. In addition, atherosclerotic disease and atherosclerotic risk factors may hinder SC blood supply visualization [9]. AKA identification rates are higher in studies using multiple detection techniques [18, 19, 41] (Fig. 25.6). 
Fig. 25.6 Frequency distribution of the side of origin in studies that used computed tomography angiography for AKA identification $[9,15-26]$

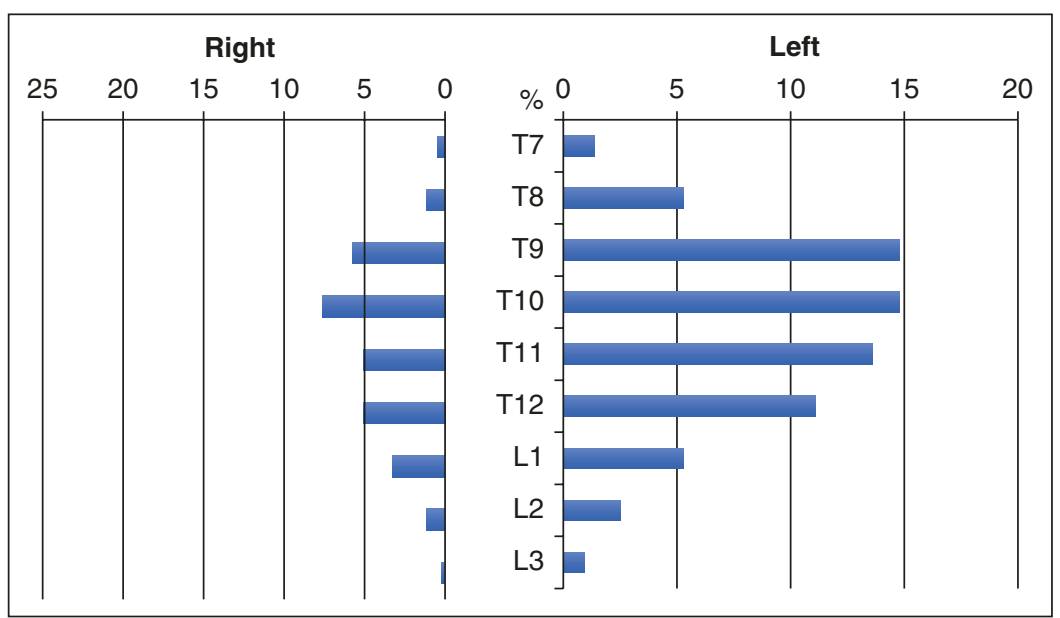

Even though magnetic resonance does not involve exposure to ionizing radiation and has a small risk for complications [28], it is not tolerated by all patients due to the long scan times [42]. The ability to discriminate between arterial supply and venous drainage is a clear advantage of MRA, while the proximity to skeletal structures is irrelevant, but special acquisition protocols, particularly fast acquisition techniques that use a strong bolus, in addition to good skill and dedication in image post-processing, are required for optimal results [28].

\subsection{Influence of Artery Detection or Presence of Artery on Postoperative Spinal Cord Ischemia}

A retrospective study using a risk model for the analysis of a database with 2235 patients from 19 European centers revealed 38 (1.7\%) cases of symptomatic spinal cord ischemia. This study indicated that endovascular closure of intercostal arteries combined with occlusion of collateral vessels supplying the spinal cord is a risk factor for symptomatic spinal cord ischemia. The mathematical algorithm employed identified that intraoperative hypotension and simultaneous closure of at least two spinal cord vascular territories were relevant in the development of ischemia and that extensive coverage of intercostal arteries alone is not associated with symptomatic spinal cord ischemia [30]. Also, Murakami et al. suggested that the AKA is not the only source of SC blood supply [43]. Nevertheless, retrospective analysis of 457 patients and their in-hospital complications revealed that paraplegia and paraparesis were significantly associated with a length of the covered aorta $>20 \mathrm{~cm}$ [44], which supports the importance of segmental arteries for SC blood supply. Yingbin et al. demonstrated the importance of identifying the AKA for selecting long endografts in cases of thoracic aortic dissection [45].

The mechanism of spinal cord ischemia after thoracic endovascular aortic repair (TEVAR) has not been fully clarified and appears to be multifactorial [3, 33]. Spinal cord perfusion depends on the gradient between arterial pressure and cerebrospinal fluid pressure [33].

\subsection{Spinal Cord Visualization Technique}

For AKA visualization [9, 21, 46], axial images are scrolled over at a large magnification and examined for the presence of two enhanced spots in the spinal cord, corresponding to the ASA and AKA, while tracing their cranialcaudal trajectory. Next, three-dimensional multiplanar reconstruction is used, enabling the simultaneous visualization, in three windows, 


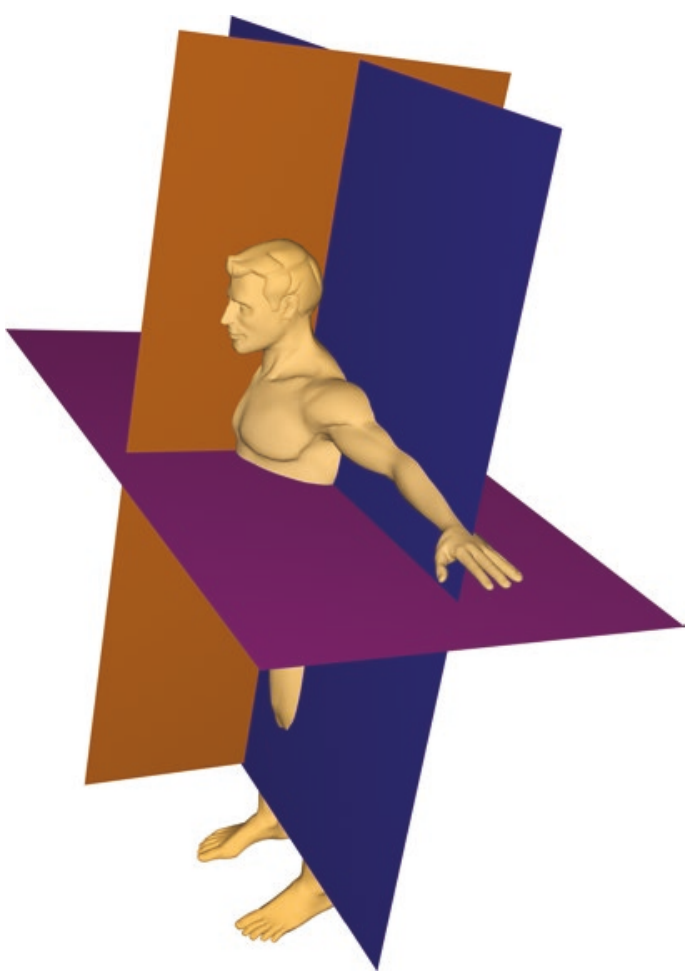

Fig. 25.7 Oblique planes used for AKA localization on three-dimensional multiplanar reconstruction of three oblique planes at $90^{\circ}$ in relation to each other (Fig. 25.7). The entire spinal cord can be visualized by moving the crosshair. A video illustrating the technique is available at http:// vascular.cc/aka.html, and an AKA identification prediction model can be seen here https://vascular.pro/aka-model.

The crosshair is placed on the spinal cord at the level of the last thoracic vertebrae, and a sagittal view is displayed in the upper left window. By adjusting the position and angle of the crosshair to cover most of the spinal cord longitudinally in the upper left window and adjusting slice thickness using the maximum intensity projection (MIP) algorithm and "windowing" (apparent Hounsfield scale), an oblique coronal or paracoronal view of the spinal cord is produced in the large window. Tilting the crosshair and scrolling over the images along the anteroposterior direction allows a quick exploration of the entire spinal cord (Fig. 25.9) [21].

The ASA is identified, in the anterior aspect of the spinal cord, as a thin longitudinal vessel (Fig. 25.8a), whereas the AKA is readily identified by its "hairpin" appearance, supplying the
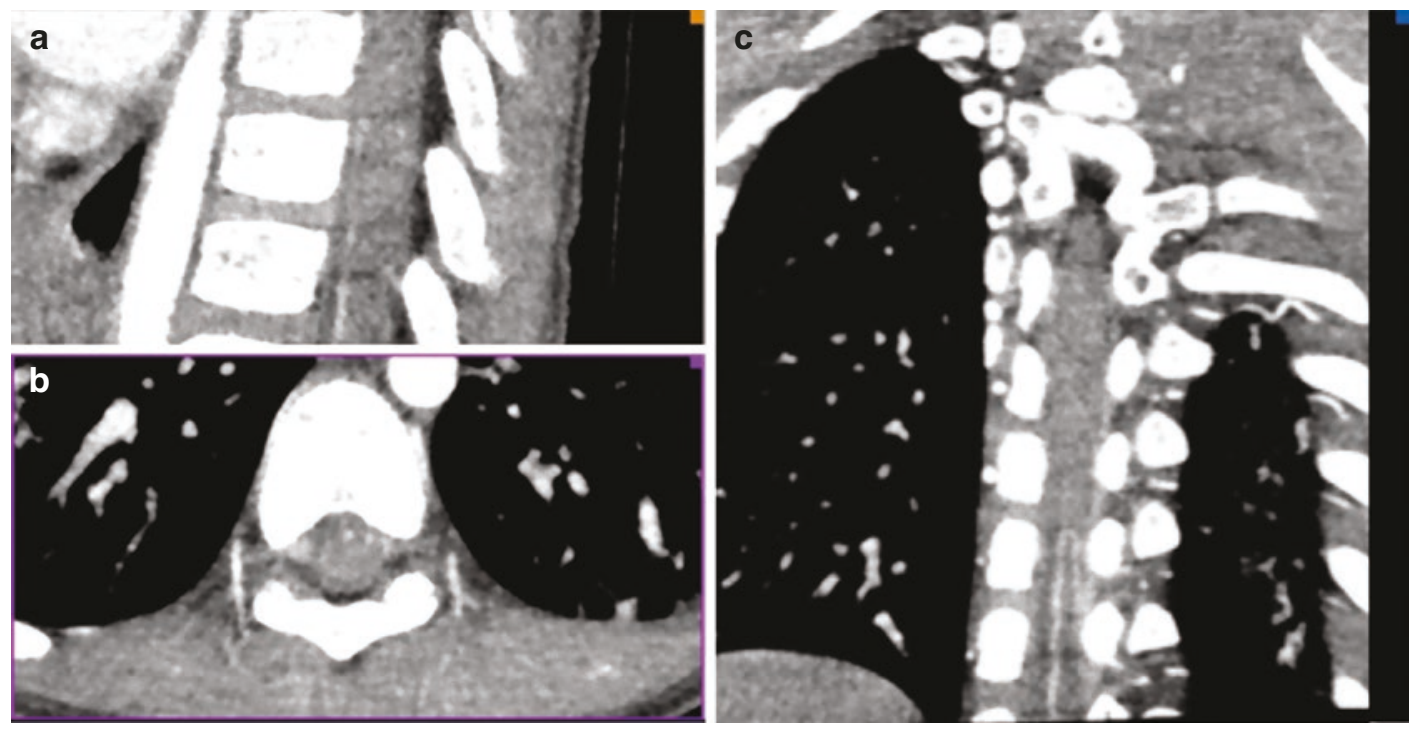

Fig. 25.8 OsiriX software window. The green arrow shows the ASA, and the red arrow shows the AKA. (a) Sagittal view. (b) Axial view. (c) Coronal oblique view 
anterior spinal artery, in a paracoronal view using two-dimensional multiplanar reconstruction (MPR) (Figs. 25.8c and 25.9).

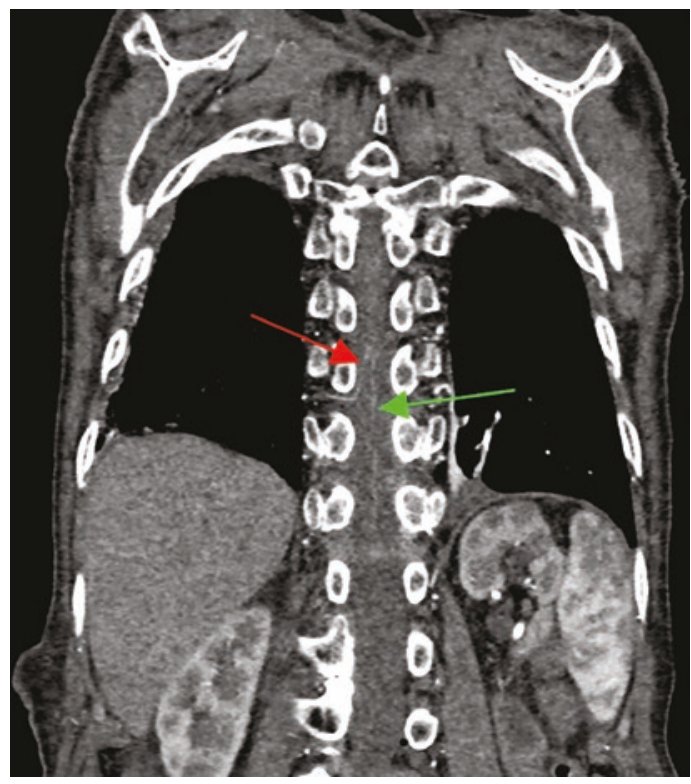

Fig. 25.9 Three-dimensional MPR oblique view showing the AKA (red arrow) with its typical "hairpin" appearance and the ASA (green arrow)
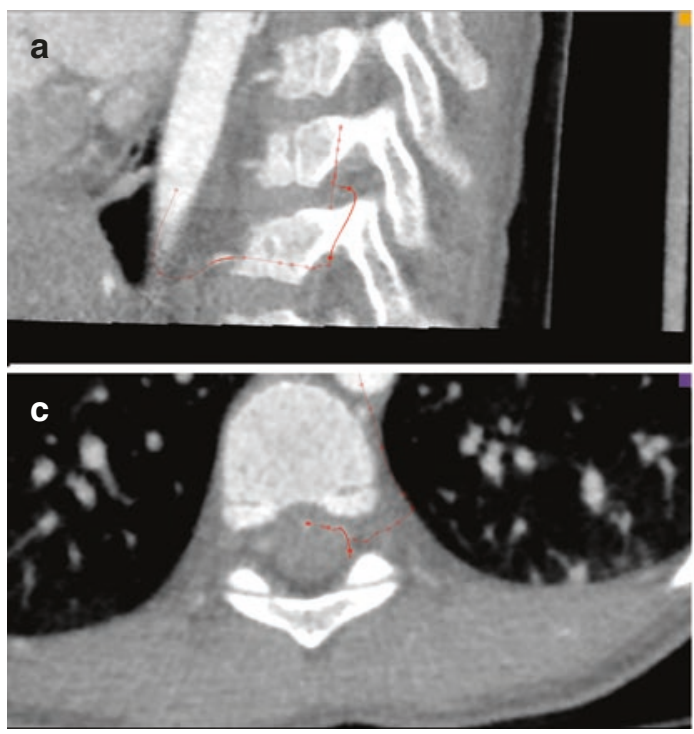

Fig. 25.10 (a-c) Oblique views showing the threedimensional path of the AKA. (d) Continuity of the AKA (red arrow) from the aorta (yellow arrow) through the intercostal artery (blue arrow) and ASA (green arrow) on
The identification of the AKA and ASA is based on the following criteria:

- Continuity of the AKA traceable to vessels of known arterial nature such as the intercostal artery or aorta (Fig. 25.10) [16, 19, 20, 36]. Continuity with arteries is certainly a highly relevant factor; however, this is not always achieved and other criteria are needed [16, 19, 20, 28, 36].

- Simultaneous identification of the AKA and ASA as two enhanced spots in the ventral aspect of the spinal cord on consecutive axial scans $[19,20,28]$.

- Characteristic anatomic relationship of the two vessels, i.e., "hairpin" shape (Fig. 25.3) [19].

- Failure of venous enhancement and visualization of the posterior spinal vein and other veins surrounding the spinal column (intercostal, lumbar, and azygos veins) [28].

The AKA can be identified with computed tomography angiography in approximately $70 \%$ of cases [9, 17-20, 26, 27, 38, 41, 47-50], and this imaging modality is routinely used in the
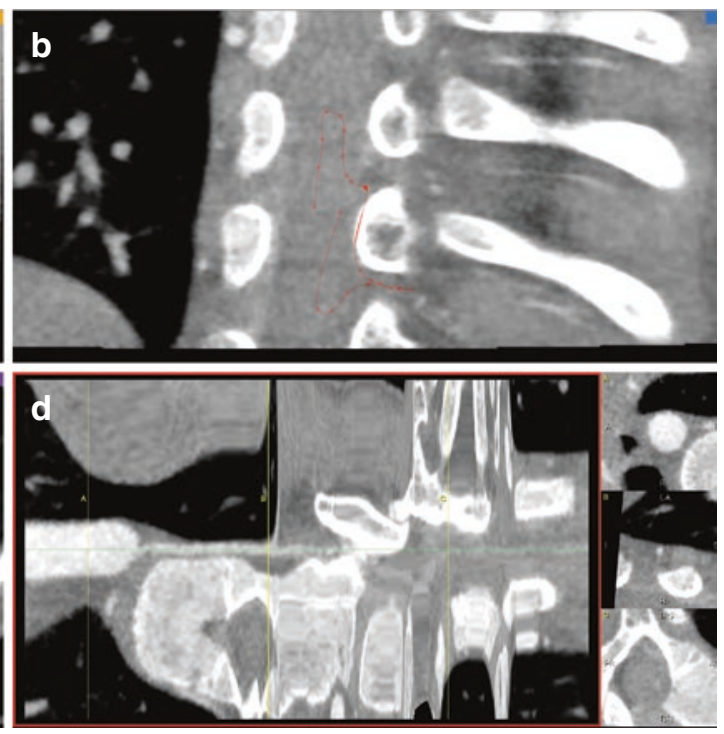

three-dimensional curved multiplanar reconstruction, which reconstructs the course of the vessel from its origin in the aorta through the spinal cord 
preoperative assessment of thoracoabdominal aortic aneurysms. The imaging acquisition protocol for SC blood supply visualization is similar to standard angio-CT protocols used in most centers.

\subsection{Conclusion}

When the risk of intraoperative closure of two vascular territories supplying the spinal cord [30] is identified in the presurgical planning of aortic aneurysm repair, AKA disruption-or at least that of collateral vessels - can be prevented with prior knowledge of its location using the method described here.

If the AKA identification method proposed cannot be applied to a patient, the surgical team should then rely on anatomic studies [9] that show the existence of a critical area of great importance for SC circulation between the levels of $\mathrm{T} 9$ and $\mathrm{T} 12$. This area requires special attention from the surgeon to preserve the AKA as well as if possible the other spinal cord blood supply sources.

\section{References}

1. Greenberg RK, Lytle B. Endovascular repair of thoracoabdominal aneurysms. Circulation. 2008;117(17):2288-96.

2. Svensson LG, Crawford ES, Hess KR, Coselli JS, Safi HJ. Experience with 1509 patients undergoing thoracoabdominal aortic operations. J Vasc Surg. 1993;17(2):357-68.

3. Chiesa R, Melissano G, Bertoglio L, Amato ACM, Tshomba Y, Civilini E, et al. The risk of spinal cord ischemia during thoracic aorta endografting. Acta Chir Belg. 2008;108:492-502.

4. Gottardi R, Dumfarth J, Holfeld J, Schoder M, Funovics M, Laufer G, et al. Symptomatic spinal cord malperfusion after stent-graft coverage of the entire descending aorta. Eur J Cardiothorac Surg. 2010;37(5):1081-5.

5. Eggebrecht $H$, Nienaber CA, Neuhäuser M, Baumgart D, Kische S, Schmermund A, et al. Endovascular stent-graft placement in aortic dissection: a metaanalysis. Eur Heart J. 2006;27(4):489-98.

6. Czerny M, Funovics M, Sodeck G, Dumfarth J, Schoder M, Juraszek A, et al. Long-term results of thoracic endovascular aortic repair in atherosclerotic aneurysms involving the descending aorta. J Thorac Cardiovasc Surg. 2010;140(6 Suppl):S179-84.

7. Buth J, Harris PL, Hobo R, van Eps R, Cuypers P, Duijm L, Tielbeek X. Neurologic complications associated with endovascular repair of thoracic aortic pathology: incidence and risk factors. A study from the european collaborators on stent/graft techniques for aortic aneurysm repair (EUROSTAR) registry. J Vasc Surg. 2007;46(6):1103-10.

8. Melissano G, Civilini E, Bertoglio L, Calliari F, Campos Moraes Amato A, Chiesa R. Angio-CT imaging of the spinal cord vascularisation: a pictorial essay. Eur J Vasc Endovasc Surg. 2010;39(4):436-40.

9. Amato ACM, Parga Filho JR, Stolf NAG. Influential factors on the evaluation of Adamkiewicz artery using a 320-detector row computed tomography device. Ann Vasc Surg. 2017;44:136-45.

10. Amato ACM, Parga Filho JR, Stolf NAG. Predictors of Adamkiewicz artery and anterior spinal artery detection through computerized tomographic angiography. SAGE Open Med. 2017;5:2050312117711599.

11. Amato ACM, Stolf NAG. Anatomy of spinal blood supply. J Vasc Bras. 2015;14(3):248-52.

12. Thron AK. Vascular anatomy of the spine. Oxford: Oxford University Press; 2002.

13. Thron AK, Rossberg C. Vascular anatomy of the spinal cord: neuroradiological investigations and clinical syndromes. New York: Springer; 1988.

14. Thron AK. Vascular anatomy of the spinal cord: neuroradiological investigations and clinical syndromes. New York: Springer-Verlag; 1989.

15. Kudo K, Terae S, Asano T, Oka M, Kaneko K, Ushikoshi S, Miyasaka K. Anterior spinal artery and artery of Adamkiewicz detected by using multi-detector row CT. AJNR Am J Neuroradiol. 2003;24(1):13-7.

16. Uotani K, Yamada N, Kono AK, Taniguchi T, Sugimoto K, Fujii M, et al. Preoperative visualization of the artery of Adamkiewicz by intra-arterial CT angiography. AJNR Am J Neuroradiol. 2008;29(2):314-8.

17. Nojiri J, Matsumoto K, Kato A, Miho T, Furukawa K, Ohtsubo S, et al. The Adamkiewicz artery: demonstration by intra-arterial computed tomographic angiography. Eur J Cardiothorac Surg. 2007;31(2):249-55.

18. Yoshioka K, Niinuma H, Ohira A, Nasu K, Kawakami T, Sasaki M, Kawazoe K. MR angiography and CT angiography of the artery of Adamkiewicz: noninvasive preoperative assessment of thoracoabdominal aortic aneurysm. Radiographics. 2003;23(5):1215-25.

19. Yoshioka K, Niinuma $H$, Ehara S, Nakajima $T$, Nakamura M, Kawazoe K. MR angiography and CT angiography of the artery of Adamkiewicz: state of the art. Radiographics. 2006;26(Suppl 1):S63-73.

20. Takase K, Sawamura Y, Igarashi K, Chiba Y, Haga K, Saito H, Takahashi S. Demonstration of the artery of Adamkiewicz at multi- detector row helical CT. Radiology. 2002;223(1):39-45.

21. Melissano G, Amato ACM, Bertoglio L, Civilini E, Civelli V, Coppi G, et al. Demonstration of the Adamkiewicz artery by multidetector computed 
tomography angiography analysed with opensource software OsiriX. Eur J Vasc Endovasc Surg. 2009;37(4):395-400.

22. Nishimura J, Lee J, Koike S, Kurihara H, Ozawa $\mathrm{Y}$, Abe A, et al. Identification of the segmental artery feeding the anterior spinal artery: correlation between helical CT and angiography. Radiat Med. 2005;23(4):271-6.

23. von Tengg-Kobligk H, Böckler D, Jose TM, Ganten M, Kotelis D, Nagel S, et al. Feeding arteries of the spinal cord at CT angiography before and after thoracic aortic endografting. J Endovasc Ther. 2007;14(5):639-49.

24. Nakayama Y, Awai K, Yanaga Y, Nakaura T, Funama Y, Hirai T, Yamashita Y. Optimal contrast medium injection protocols for the depiction of the Adamkiewicz artery using 64-detector CT angiography. Clin Radiol. 2008;63(8):880-7.

25. Zhao S, Logan L, Schraedley P, Rubin GD. Multidetector CT angiography for the assessment of anterior spinal artery and artery of Adamkiewicz patency in patients suspected of having thoracic aortic pathology. J Geriatr Cardiol. 2006;3(1):52-6.

26. Ou P, Schmit P, Layouss W, Sidi D, Bonnet D, Brunelle F. CT angiography of the artery of Adamkiewicz with 64-section technology: first experience in children. AJNR Am J Neuroradiol. 2007;28(2):216-9.

27. Takase K, Akasaka J, Sawamura Y, Ota H, Sato A, Yamada T, et al. Preoperative MDCT evaluation of the artery of Adamkiewicz and its origin. J Comput Assist Tomogr. 2006;30(5):716-22.

28. Melissano G, Chiesa R. Advances in imaging of the spinal cord vascular supply and its relationship with paraplegia after aortic interventions. A review. Eur J Vasc Endovasc Surg. 2009;38(5):567-77.

29. Griepp RB, Griepp EB. Spinal cord perfusion and protection during descending thoracic and thoracoabdominal aortic surgery: the collateral network concept. Ann Thorac Surg. 2007;83(2):S865-9.

30. Czerny M, Eggebrecht H, Sodeck G, Verzini F, Cao P, Maritati G, et al. Mechanisms of symptomatic spinal cord ischemia after TEVAR: insights from the european registry of endovascular aortic repair complications (eurec). J Endovasc Ther. 2012;19(1):37-43.

31. Griepp R, Luozzo GD, Schray D, Stefanovic A, Geisbüsch S, Randall BRB. The anatomy of the spinal cord collateral circulation. Ann Cardiothorac Surg. 2012;1(3):350-7.

32. Kieffer E, Richard T, Chiras J, Godet G, Cormier E. Preoperative spinal cord arteriography in aneurysmal disease of the descending thoracic and thoracoabdominal aorta: preliminary results in 45 patients. Ann Vasc Surg. 1989;3(1):34-46.

33. Chiesa R, Melissano G, Marrocco-Trischitta MM, Civilini E, Setacci F. Spinal cord ischemia after elective stent-graft repair of the thoracic aorta. J Vasc Surg. 2005;42(1):11-7.

34. Forbes G, Nichols DA, Jack CR, Ilstrup DM, Kispert DB, Piepgras DG, et al. Complications of spinal cord arteriography: prospective assessment of risk for diagnostic procedures. Radiology. 1988;169(2):479-84.

35. Schurink GW, Nijenhuis RJ, Backes WH, Mess W, de Haan MW, Mochtar B, Jacobs MJ. Assessment of spinal cord circulation and function in endovascular treatment of thoracic aortic aneurysms. Ann Thorac Surg. 2007;83(2):S877-81.

36. Yamada N, Okita Y, Minatoya K, Tagusari O, Ando M, Takamiya M, Kitamura S. Preoperative demonstration of the Adamkiewicz artery by magnetic resonance angiography in patients with descending or thoracoabdominal aortic aneurysms. Eur J Cardiothorac Surg. 2000;18(1):104-11.

37. Kawaharada N, Morishita K, Fukada J, Yamada A, Muraki S, Hyodoh H, Abe T. Thoracoabdominal or descending aortic aneurysm repair after preoperative demonstration of the Adamkiewicz artery by magnetic resonance angiography. Eur J Cardiothorac Surg. 2002;21(6):970-4.

38. Nijenhuis RJ, Gerretsen S, Leiner T, Jacobs MJ, van Engelshoven JM, Backes WH. Comparison of 0.5-M gd-dtpa with 1.0-M gadobutrol for magnetic resonance angiography of the supplying arteries of the spinal cord in thoracoabdominal aortic aneurysm patients. J Magn Reson Imaging. 2005;22(1):136-44.

39. Hyodoh H, Shirase R, Akiba H, Tamakawa M, Hyodoh $\mathrm{K}$, Yama $\mathrm{N}$, et al. Double-subtraction maximum intensity projection MR angiography for detecting the artery of Adamkiewicz and differentiating it from the drainage vein. J Magn Reson Imaging. 2007;26(2):359-65.

40. Hyodoh H, Kawaharada N, Akiba H, Tamakawa M, Hyodoh K, Fukada J, et al. Usefulness of preoperative detection of artery of Adamkiewicz with dynamic contrast-enhanced MR angiography. Radiology. 2005;236(3):1004-9.

41. Nijenhuis RJ, Jacobs MJ, Schurink GW, Kessels AG, van Engelshoven JM, Backes WH. Magnetic resonance angiography and neuromonitoring to assess spinal cord blood supply in thoracic and thoracoabdominal aortic aneurysm surgery. J Vasc Surg. 2007;45(1):71-7.

42. Katz RC, Wilson L, Frazer N. Anxiety and its determinants in patients undergoing magnetic resonance imaging. J Behav Ther Exp Psychiatry. 1994;25(2):131-4.

43. Murakami H, Kawahara N, Tomita K, Demura S, Kato S, Yoshioka K. Does interruption of the artery of Adamkiewicz during total en bloc spondylectomy affect neurologic function? Spine (Phila Pa 1976). 2010;35(22):E1187-92.

44. Fattori R, Nienaber CA, Rousseau H, Beregi JP, Heijmen R, Grabenwöger M, et al. Results of endovascular repair of the thoracic aorta with the talent thoracic stent graft: the talent thoracic retrospective registry. J Thorac Cardiovasc Surg. 2006;132(2):332-9.

45. Yingbin J, Jiefei M, Jian L, Yonghui S, Haiyan P, Baimeng Z, Weigoo F. Evaluation of the thoracic aortic dissection treated by endografts covering a longer distance of aorta according to the location of 
the Adamkiewicz artery. Thorac Cardiovasc Surg. 2013;61(07):569-74

46. Amato ACM, Melissano G, Giovanni C, Civilini E, Civelli V, Calori G, et al. Available from: http://vascular.cc/aka.html. Accessed 18 Dec 2012.

47. Nijenhuis RJ, Jacobs MJ, Jaspers K, Reinders M, Reijnders M, van Engelshoven JM, et al. Comparison of magnetic resonance with computed tomography angiography for preoperative localization of the Adamkiewicz artery in thoracoabdominal aortic aneurysm patients. J Vasc Surg. 2007;45(4):677-85.

48. Boll DT, Bulow H, Blackham KA, Aschoff AJ, Schmitz BL. MDCT angiography of the spinal vas- culature and the artery of Adamkiewicz. AJR Am J Roentgenol. 2006;187(4):1054-60.

49. Nijenhuis RJ, Mull M, Wilmink JT, Thron AK, Backes WH. MR angiography of the great anterior radiculomedullary artery (Adamkiewicz artery) validated by digital subtraction angiography. AJNR Am J Neuroradiol. 2006;27(7):1565-72.

50. Nijenhuis RJ, Jacobs MJ, van Engelshoven JM, Backes WH. MR angiography of the Adamkiewicz artery and anterior radiculomedullary vein: postmortem validation. AJNR Am J Neuroradiol. 2006;27(7): 1573-5. 